\title{
CHROMOSOMAL POLYMORPHISM AND CAPACITY FOR INCREASE UNDER NEAR OPTIMAL CONDITIONS *
}

\author{
SHIGERU OHBA \\ The Rockefeller University, New York, and Department $\dagger$ \\ of Biology, Tokyo Metropolitan University
}

Received I4.vi.66

\section{INTRODUCTION}

THE problem of comparing the adaptedness, or fitness, of populations in different environments has in recent years attracted the attention of several investigators. In Drosophila, estimates of relative fitness of populations have been attempted by comparing the fecundity (Wallace, I959), the size of the flies and the biomass produced per unit of food (Beardmore, Dobzhansky and Pavlovsky, I96o; Battaglia and Smith, I96I; Strickberger, I963a; Ayala, I965a, $b$ ) and the competitive ability against indicator species (Barker, I963, I965; Strickberger, $1963 b)$. A statistic called "the innate capacity for increase" (Andrewartha and Birch, I954), which estimates the geometric rate of increase in numbers at optimal density with all other environmental factors defined, has been introduced as a most useful measure to compare the fitnesses of different populations. Calculating the value of the innate capacity for increase, $r_{m}$, Birch, Dobzhansky, Elliott and Lewontin ( 1963 ) found significant differences between five geographically separated populations of Drosophila serrata. Dobzhansky, Lewontin and Pavlovsky (1964) made comparisons of $r_{m}$ among ten Drosophila pseudoobscura experimental populations which differed in chromosomal composition; they found differences between some of the populations, in addition to a strong effect of temperatures ( $16^{\circ}$ vs. $25^{\circ} \mathrm{C}$.).

The experiments of Dobzhansky, Lewontin and Pavlovsky were deliberately made under conditions which deviated from possible optimal ones. They utilised flies which developed under conditions of severe competition and crowding in population cages, since their purpose was to investigate the capacities for increase in populations just released from environmental constraints. The purpose of the present study is, on the contrary, to estimate values of $r_{m}$ close to their possible maxima. The conditions of food and temperature were hence made as close to optimal as practicable. An experiment at suboptimal food conditions was run for comparison. Chromosomally monomorphic and polymorphic populations were compared.

* This work was made possible by grants of N.S.F. (GB-3585) and of the Japan-U.S. Cooperative Science Program, Biol. I 7 , enabling the author to work at the Rockefeller University.

$\dagger$ Present address: Department of Biology, Tokyo Metropolitan University, Setagaya-ku, Tokyo. 


\section{MATERIALS AND TECHNIQUES}

Drosophila pseudoobscura populations with different gene arrangements in the third chromosomes were chosen. Balanced polymorphism for these gene arrangements are commonly observed in natural populations, and much analytical work relevant to the present study is published.

Two monomorphic and four polymorphic populations were used. Their progenitors were derived from flies collected at Pinon Flat, California. Two populations polymorphic for $\mathrm{AR}$ or $\mathrm{CH}$ gene arrangement, a monomorphic $\mathrm{AR}$ population and a monomorphic $\mathrm{CH}$ population, were prepared by intercrossing all the $\mathrm{AR}$ or $\mathrm{CH}$ strains (twelve each). The two polymorphic populations were identical in chromosomal constitution but different in the origin of their cytoplasm, since one was obtained by intercrossing females of AR strains to $\mathrm{CH}$ males (AR/CH, with AR strain cytoplasm) and the other by intercrossing $\mathrm{CH}$ females with $\mathrm{AR}$ males. Equal numbers of virgin females and males of $F_{1}$ flies were collected from each cross and placed together in bottles. After three days they were divided into groups of about 25 pairs and transferred into culture vials containing 8 per cent. dry yeast medium. For each population, about 30 groups of flies were used as parents of the generation tested. Two further polymorphic populations contained five different gene arrangements (AR, CH, ST, TL, PP). About rooo eggs of the second generation were sampled by putting in two extra cups with 8 per cent. yeast medium. Flies emerging from these cups were divided into groups of about 25 pairs and used as parents. These two extremely polymorphic populations are not exactly comparable to the four less polymorphic populations, because they were derived from strains collected in a different locality (Mather, California).

\section{Culture conditions}

To obtain controlled food conditions, a special medium (Ohba, I96I) was used for all the cultures. It contains :

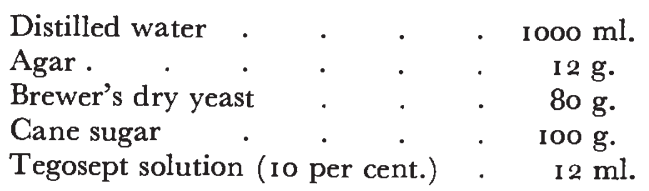

Tests indicated that the 8 per cent. dry yeast medium was almost equivalent to the 20 per cent. fresh yeast medium and, therefore, it was adopted as a standard medium offering nearly optimal food conditions to both adults and larvæ. By changing the amount of yeast in this medium, different well-defined nutritional levels can easily be obtained. A 2 per cent. medium was chosen as a suboptimal level.

Small vials, $2 \cdot 2-2 \cdot 3 \mathrm{~cm}$. in inside diameter, $9 \mathrm{~cm}$. in height and filled with about $6 \mathrm{ml}$. of medium, were used. All cultures, both experimental and parental, were kept in an incubator in which the temperature was maintained at $25^{\circ} \pm 0 \cdot 2^{\circ} \mathrm{C}$. Relative humidity was almost always in the range of $55^{-6} 65$ per cent. throughout the course of these experiments.

\section{Measurement of the components of the innate capacity for increase}

(a) Hatchability.-The viability of the immature stages was measured in three steps: the hatchability (percentage of eggs hatched); larval viability (percentage of first instar larvæ surviving to pupate); and pupal viability (percentage of pupæ giving rise to adults). The latter two stages were usually combined as "pre-adult viability". This method makes it possible to control the larval density and to obtain information about the distribution of viabilities in the three pre-adult stages.

For the hatchability tests a group of parent flies was put into a large sterilised vial with a paper spoon with a definite amount of the yeast medium, 8 per cent. or 2 per cent. To make the eggs more conspicuous, charcoal was added to the medium. After two hours the parent flies were removed, and the eggs counted. Only spoons 
with 50 to 150 eggs were utilised, put back into vials and kept in an incubator. To protect the medium from desiccation, all vials were placed in a box containing a wet paper towel and wrapped in plastic. After two days the larvæ and the medium were washed out with water into a glass dish, and the larvæ were picked up one by one to determine the number of eggs which hatched. The hatchability is given as the ratio of larvæ to eggs.

(b) Viability and the duration of the development in pre-adult stages. - The same flies used in the hatchability tests were used as parents. Techniques to measure the larval and pupal viabilities and development time are described in Ohba (1961). A group of flies was put into a fresh vial with 2 per cent. medium and allowed to oviposit for four hours. Thirty-two to thirty-six hours after oviposition, first instar larvæ were washed from the surface of the medium with 70 per cent. alcohol, into a glass dish. They were picked up within 10 minutes to avoid the harmful effect of alcohol. Forty larvæ were put in a vial with 8 per cent. or 2 per cent. medium, at a density of Io larvæ per $\mathrm{cm} .{ }^{2}$ of medium surface. This density is close to the maximal in the optimal range of viabilities, development time and body size on the 8 per cent. medium (Ohba, in preparation). The number and sex of the flies which emerged were recorded every day at midpoint of the ovipositing period. Finally, the number of unhatched pupx was examined. Usually 25 but sometimes 30 replicate vials were set up for each population at the two levels of medium.

(c) Longevity of the adults.- The flies emerging from the cultures in the survival experiments were used for longevity measurements. Ten pairs of flies o- 6 hours old were placed in a vial with medium, 8 per cent. for flies grown in the 8 per cent. medium and 2 per cent. for those from the 2 per cent. medium. The vials were kept horizontally to avoid accidental death of flies on the medium surface. Each day dead males and females were recorded and removed. The surviving flies were transferred to new vials every two (8 per cent. medium) or three ( 2 per cent. medium) days. All longevity tests were performed concurrently, with ro replicates for each population at the two medium levels.

(d) Fecundity.- - Lifetime egg-laying schedules were determined for flies from the same source as those used in the longevity experiments. Five females and eight males were put into a large sterilised vial with a spoon like that in the hatchability tests. Every possible precaution was taken to minimise environmental fluctuations, since fecundity is extremely sensitive to various environmental factors. The flies were transferred daily to new vials. Fecundity measurements on all populations started at the same time, with six (8 per cent. medium) or five ( 2 per cent. medium) replicates. The maximum oviposition period was go days, and the grand total number of eggs counted was 269,260 .

(e) Body size.-Although body size is not a component of the innate capacity for increase, it was examined for relationships between the body size and fecundity or longevity. Forty females and forty males were taken at random from the same group of flies as those examined for longevity and fecundity. Their wing length, measured as the length of the third longitudinal vein from the outer margin on the anterior crossvein to the tip of the wing, was measured as described in Anderson (1966).

\section{Estimation of the innate capacity for increase $\left(r_{m}\right)$}

The calculation of $r_{m}$ basing upon Lotka's formula

$$
\int_{0}^{\infty} e^{-r} m^{x} l_{x} m_{x} d_{x}=\mathrm{I}
$$

has been discussed in Birch (1948), Birch, Dobzhansky, Elliott and Lewontin (1963) and Dobzhansky, Lewonti and Pavlovsky (1964). The formula used to calculate $r_{m}$ in this study was:

$$
h a^{\prime} \sum_{0}^{t} e^{-r_{m}(x+F)} l_{x} m_{x}=\mathbf{I}
$$


where $h=$ proportion of eggs hatched;

$a^{\prime}=$ proportion of first instar larvæ surviving to adults;

$t=$ maximum adult life span;

$x=$ age of an adult (in days);

$F=$ mean length in days from egg to emerging of adult flies;

$l_{x}=$ probability of survival of adults from emergence to age $x$;

$m_{x}=$ one-half the number of eggs laid by a female of age $x$;

$r_{m}=$ innate capacity for increase.

This formula is the same as used by Dobzhansky, Lewontin and Pavlovsky (1964), except for the separation of $a$ (proportion of eggs surviving to adults) into two components, $h$ and $a^{\prime}$. Newton's method of iteration was used to yield a solution; the means and variances of $r_{m}$ were calculated by a digital computer from all possible combinations of each component. To reduce the amount of calculation, however, the number of replicates of some components was reduced as shown in table I by grouping two (in $l_{x}$ ) or five (in $a$ and $F$ ) replicate vials into one. Calculation of $r_{m}$ by computer was done at the University of Chicago by Professor R. C. Lewontin.

TABLE I

The number of replicates used to calculate the means and variances of the innate capacity for increase, $\mathrm{r}_{\mathrm{m}}$

\begin{tabular}{|c|c|c|c|c|c|c|c|c|c|c|c|c|}
\hline \multirow{2}{*}{ Population } & \multicolumn{5}{|c|}{$\begin{array}{l}8 \text { per cent. } \\
\text { medium }\end{array}$} & \multirow{2}{*}{$\begin{array}{c}\text { Total } \\
\text { combination }\end{array}$} & \multicolumn{5}{|c|}{$\begin{array}{l}2 \text { per cent. } \\
\text { medium }\end{array}$} & \multirow{2}{*}{$\begin{array}{c}\text { Total } \\
\text { combination }\end{array}$} \\
\hline & $h$ & $a^{\prime}$ & $F$ & $l_{x}$ & $m_{x}$ & & $h$ & $a^{\prime}$ & $F$ & $l_{x}$ & $m_{x}$ & \\
\hline $\begin{array}{l}\mathrm{AR} \\
\mathrm{CH} \\
\mathrm{AR} / \mathrm{CH} \\
\mathrm{CH} / \mathrm{AR} \\
229 \\
234\end{array}$ & $\begin{array}{l}\text { I } \\
\text { I } \\
\text { I } \\
\text { I } \\
\text { I } \\
\text { I }\end{array}$ & $\begin{array}{l}5 \\
5 \\
5 \\
5 \\
6 \\
6\end{array}$ & $\begin{array}{l}5 \\
5 \\
5 \\
5 \\
6 \\
6\end{array}$ & $\begin{array}{l}5 \\
5 \\
5 \\
5 \\
5 \\
5\end{array}$ & $\begin{array}{l}6 \\
6 \\
6 \\
6 \\
6 \\
6\end{array}$ & $\begin{array}{r}750 \\
750 \\
750 \\
750 \\
\text { 1080 } \\
1080\end{array}$ & $\begin{array}{l}\text { I } \\
\text { I } \\
\text { I } \\
\text { I } \\
\text { I } \\
\text { I }\end{array}$ & $\begin{array}{l}5 \\
5 \\
5 \\
5 \\
6 \\
6\end{array}$ & $\begin{array}{l}5 \\
5 \\
5 \\
5 \\
6 \\
6\end{array}$ & $\begin{array}{l}5 \\
5 \\
5 \\
5 \\
5 \\
5\end{array}$ & $\begin{array}{l}5 \\
5 \\
5 \\
5 \\
5 \\
5\end{array}$ & $\begin{array}{l}625 \\
625 \\
625 \\
625 \\
900 \\
900\end{array}$ \\
\hline
\end{tabular}

\section{RESULTS}

(i) Hatchability

The percentage of the eggs hatched, was fairly uniform in all populations on both media (table 2). Analysis of variance made on

TABLE 2

Percentage mean and standard error of hatchability of eggs laid on 8 per cent. and 2 per cent media

\begin{tabular}{|l|l|l|}
\hline \multirow{2}{*}{ Population } & \multicolumn{2}{|c|}{ Medium } \\
\cline { 2 - 3 } & 8 per cent. & 2 per cent. \\
\hline & & \\
\hline AR & $96 \cdot 5 \pm 0 \cdot 7$ & $96 \cdot 8 \pm 0 \cdot 6$ \\
CH & $95 \cdot 2 \pm 0 \cdot 6$ & $95 \cdot 6 \pm 0 \cdot 7$ \\
AR/CH & $95 \cdot 6 \pm 0 \cdot 7$ & $96 \cdot 7 \pm 0 \cdot 5$ \\
CH/AR & $95 \cdot 8 \pm 0 \cdot 7$ & $94 \cdot 5 \pm 0 \cdot 7$ \\
229 & $96 \cdot 6 \pm 0 \cdot 5$ & $95 \cdot 7 \pm 0 \cdot 8$ \\
234 & $96 \cdot 6 \pm 0 \cdot 5$ & $96 \cdot 1 \pm 0 \cdot 6$ \\
\hline
\end{tabular}




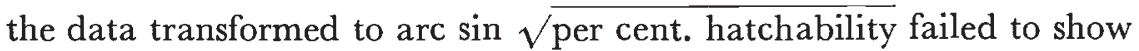
significant differences between populations, or media, or between replicates. The mean hatchability of each population was used to calculate the value of $r_{m}$.

\section{(ii) Viability in larval and pupal stages}

The data is summarised in table 3. Analysis of variance on total pre-adult viability transformed to arc $\sin \sqrt{\text { per cent. viability }}$ (table 4 )

TABIE 3

Larval, pupal and total pre-adult viabilities (percentage) on the two media

\begin{tabular}{|c|c|c|c|c|c|c|c|c|}
\hline \multirow{3}{*}{ Population } & \multicolumn{4}{|c|}{8 per cent. medium } & \multicolumn{4}{|c|}{2 per cent. medium } \\
\hline & \multirow{2}{*}{$\begin{array}{c}\text { Larval } \\
\text { viability }\end{array}$} & \multirow{2}{*}{$\begin{array}{c}\text { Pupal } \\
\text { viability }\end{array}$} & \multicolumn{2}{|c|}{$\begin{array}{l}\text { Total pre-adult } \\
\text { viability }\end{array}$} & \multirow{2}{*}{$\begin{array}{c}\text { Larval } \\
\text { viability }\end{array}$} & \multirow{2}{*}{$\begin{array}{l}\text { Pupal } \\
\text { viability }\end{array}$} & \multicolumn{2}{|c|}{$\begin{array}{l}\text { Total pre-adult } \\
\text { viability }\end{array}$} \\
\hline & & & Mean \pm S.E. & C.V. & & & Mean \pm S.E. & C.V. \\
\hline $\begin{array}{l}\mathrm{AR} \\
\mathrm{CH} \\
\mathrm{AR} / \mathrm{CH} \\
\mathrm{CH} / \mathrm{AR} \\
229 \\
234\end{array}$ & $\begin{array}{l}93 \cdot 0 \\
94 \cdot 3 \\
95 \cdot 5 \\
92 \cdot 9 \\
92 \cdot 8 \\
93 \cdot 6\end{array}$ & $\begin{array}{l}95 \cdot 4 \\
95 \cdot 4 \\
96 \cdot 4 \\
94 \cdot 1 \\
95 \cdot 5 \\
97 \cdot 4\end{array}$ & $\begin{array}{l}88 \cdot 7 \pm \mathrm{r} \cdot 5 \\
90 \cdot 0 \pm \mathrm{r} \cdot 4 \\
92 \cdot \mathrm{r} \pm \mathrm{r} \cdot 6 \\
87 \cdot 4 \pm \mathrm{r} \cdot 5 \\
89^{\cdot} \mathrm{I} \pm \mathrm{r} \cdot 3 \\
9 \mathrm{I} \cdot 2 \pm \mathrm{r} \cdot 2\end{array}$ & $\begin{array}{l}8 \cdot 5 \\
7 \cdot 8 \\
8 \cdot 7 \\
8 \cdot 6 \\
8 \cdot 0 \\
7 \cdot 4\end{array}$ & $\begin{array}{l}87 \cdot 8 \\
90 \cdot 5 \\
94 \cdot 7 \\
72 \cdot 0 \\
75 \cdot 4 \\
90 \cdot 1\end{array}$ & $\begin{array}{l}78 \cdot 6 \\
82 \cdot 4 \\
79 \cdot 4 \\
83 \cdot 6 \\
84 \cdot 0 \\
80 \cdot 2\end{array}$ & $\begin{array}{l}69 \cdot 0 \pm 2 \cdot 3 \\
74 \cdot 6 \pm 2 \cdot 4 \\
75 \cdot 2 \pm 2 \cdot 2 \\
60 \cdot 2 \pm 3 \cdot 4 \\
63 \cdot 3 \pm 2 \cdot 2 \\
72 \cdot 3 \pm 2 \cdot 1\end{array}$ & $\begin{array}{l}16 \cdot 7 \\
16 \cdot 1 \\
14 \cdot 6 \\
28 \cdot 2 \\
19 \cdot 0 \\
15 \cdot 9\end{array}$ \\
\hline
\end{tabular}

TABLE 4

Analysis of variance for total pre-adult viability

\begin{tabular}{|c|c|c|c|c|}
\hline Source & Sum of square & D.F. & Mean square & F \\
\hline $\begin{array}{l}\text { Medium } \\
\text { Population } \\
\text { Interaction } \\
\text { Error }\end{array}$ & $\begin{array}{r}21389 \cdot 40 \\
2270 \cdot 87 \\
372 \cdot 87 \\
20077 \cdot 17\end{array}$ & $\begin{array}{r}I \\
5 \\
5 \\
308\end{array}$ & $\begin{array}{r}2 \mathrm{I} 389.40 \\
454 . \mathrm{I} 7 \\
74.57 \\
65.19\end{array}$ & $\begin{array}{c}328 \cdot 13^{* * *} \\
6 \cdot 97^{* * *} \\
\mathrm{I} \cdot \mathrm{I} 4\end{array}$ \\
\hline Total & $44 \mathrm{I} 10 \cdot 3 \mathrm{I}$ & 319 & & \\
\hline
\end{tabular}

$* * * \quad \mathrm{P}<0.005$.

shows statistically significant differences between media and populations $(\mathrm{P}<0.005)$, but no significant interaction between populations and media. Separate analyses on larval, pupal and total viabilities reveal no significant difference between populations on the 8 per cent. medium. This means that under optimal food conditions the larval and pupal viabilities, as well as the total viability, were quite similar among the six populations, without regard to either chromosomal composition or geographic origin. Under the suboptimal condition 
( 2 per cent. medium), however, Tukey's test between pairs of mean total viability showed statistically significant differences between some populations. It is also apparent from table 3 that changes in larval viability were the main source of the differences in total viability.

\section{(iii) Development time}

The mean development time from oviposition to emergence of adult flies is given in table 5 for each sex separately. Analysis of variance

TABLE 5

Development time from egg to the emergence of adult flies (days)

\begin{tabular}{|c|c|c|c|c|c|c|c|c|}
\hline & \multicolumn{4}{|c|}{8 per cent. medium } & \multicolumn{4}{|c|}{2 per cent. medium } \\
\hline & \multicolumn{2}{|c|}{ Female } & \multicolumn{2}{|l|}{ Male } & \multicolumn{2}{|c|}{ Female } & \multicolumn{2}{|l|}{ Male } \\
\hline & Mean \pm S.E. & C.V. & Mean \pm S.E. & G.V. & Mean \pm S.E. & C.V. & Mean \pm S.E. & C.V. \\
\hline $\mathrm{AR}$ & $12 \cdot 68 \pm 0 \cdot 02$ & $3 \cdot 5$ & I $3 \cdot 34 \pm 0.02$ & $3 \cdot 8$ & $14.92 \pm 0.04$ & $4 \cdot 8$ & I $5.44 \pm 0.04$ & $4 \cdot 8$ \\
\hline $\mathrm{CH}$ & $12 \cdot 63 \pm 0.02$ & $3 \cdot 0$ & $13.34 \pm 0.02$ & $3 \cdot 4$ & $14 \cdot 76 \pm 0.04$ & $5 \cdot 0$ & I $5.33 \pm 0.04$ & $4 \cdot 9$ \\
\hline $\mathrm{AR} / \mathrm{CH}$ & $12 \cdot 70 \pm 0.02$ & $3 \cdot 5$ & I $3.44 \pm 0.02$ & $3 \cdot 2$ & $15.01 \pm 0.04$ & $5^{\cdot 6}$ & $15 \cdot 44 \pm 0 \cdot 04$ & $5 \cdot 3$ \\
\hline $\mathrm{CH} / \mathrm{AR}$ & I $2 \cdot 72 \pm 0 \cdot 02$ & 3.9 & $13.41 \pm 0.02$ & $3 \cdot 4$ & $14.86 \pm 0.04$ & $4 \cdot I$ & I $5.35 \pm 0.04$ & $4 \cdot 4$ \\
\hline 229 & $12 \cdot 63 \pm 0.02$ & $3 \cdot 2$ & $13.40 \pm 0.02$ & $3 \cdot 4$ & $14.79 \pm 0.03$ & $4 \cdot I$ & $15.31 \pm 0.03$ & $4 \cdot 2$ \\
\hline 234 & $\mathrm{I} 2 \cdot 6 \mathrm{I} \pm 0 \cdot 0 \mathrm{I}$ & $2 \cdot 4$ & $13 \cdot 3 \mathrm{I} \pm 0.02$ & $3 \cdot 6$ & $14.90 \pm 0.03$ & $4 \cdot 0$ & $15 \cdot 3^{8} \pm 0 \cdot 03$ & $4 \cdot 2$ \\
\hline
\end{tabular}

shows clear main effects of both medium and of sex, but no significant effect of population nor any interaction including population (table 6).

TABLE 6

Analysis of variance on mean development time of each vial

\begin{tabular}{|c|c|c|c|c|}
\hline Source & Sum of square & D.F. & Mean square & F \\
\hline $\begin{array}{l}\text { Medium } \\
\text { Sex } \\
\text { Population } \\
\quad \mathrm{M} \times \mathrm{S} \\
\mathrm{M} \times \mathrm{P} \\
\mathrm{S} \times \mathrm{P} \\
\mathrm{M} \times \mathrm{S} \times \mathrm{P} \\
\text { Error }\end{array}$ & $\begin{array}{r}680 \cdot 68 \\
59 \cdot 47 \\
0 \cdot 99 \\
\mathrm{I} \cdot \mathrm{I} 3 \\
\mathrm{I} \cdot 09 \\
0 \cdot 20 \\
\mathrm{I} \cdot \mathrm{I} 0 \\
7 \mathrm{I} \cdot \mathrm{I} 7\end{array}$ & $\begin{array}{r}\text { I } \\
\mathrm{I} \\
5 \\
5 \\
\mathrm{I} \\
5 \\
5 \\
6 \mathrm{I} 6\end{array}$ & $\begin{array}{r}680 \cdot 680 \\
59 \cdot 470 \\
0 \cdot 198 \\
I \cdot 130 \\
0 \cdot 218 \\
0 \cdot 040 \\
0 \cdot 220 \\
0 \cdot 116\end{array}$ & $\begin{array}{c}5867 \cdot 94 * * * \\
476 \cdot 99 * * * \\
\text { I.72 } \\
9 \cdot 06 * * * \\
\text { I.88 } \\
- \\
\text { I.90 }\end{array}$ \\
\hline Total & 8 I $_{5} \cdot 83$ & 639 & & \\
\hline
\end{tabular}

The mean development time on 8 per cent. medium (12.6I-12.72 days for females and 13.31-13.44 days for males) is shorter than in any former experiments on the usual cream of wheat medium (Spassky, 1943). For example, in a comparable experiment of Dobzhansky, 
Lewontin and Pavlovsky ( I 964), the range of female mean development time was $13 \cdot 37-14.44$ days in I96I, and I 3.50-I6.46 days in I962. The variability of the development time, given as the standard error or the coefficient of variation, is small and uniform over different populations on a given medium. On the suboptimal 2 per cent. medium, the standard error is about twice that on the optimal 8 per cent. medium. The coefficient of variation also increases, but less than twice. Male flies always develop more slowly than female flies. The difference of mean development time between females and males was fairly constant over the populations, but was significantly larger on the 8 per cent. medium (0.7I5 \pm 0.016 days) than on the 2 per cent. medium (0.503 \pm 0.020 days).

(iv) Longevity of the adult flies

The mean length of adult life, with its standard error and coefficient of variation, is tabulated in table 7 for each sex and medium. It is

TABLE 7

Longevity of adult flies (in days)

\begin{tabular}{|c|c|c|c|c|c|c|c|c|}
\hline \multirow{3}{*}{ Population } & \multicolumn{4}{|c|}{8 per cent. medium } & \multicolumn{4}{|c|}{2 per cent. medium } \\
\hline & \multicolumn{2}{|c|}{ Female } & \multicolumn{2}{|l|}{ Male } & \multicolumn{2}{|c|}{ Female } & \multicolumn{2}{|l|}{ Male } \\
\hline & $\operatorname{Mean} \pm$ S.E. & C.V. & Mean \pm S.E. & C.V. & Mean \pm S.E. & C.V. & Mean \pm S.E. & G.V. \\
\hline $\mathrm{AR}$ & $58 \cdot 7 \pm \mathrm{I} \cdot 6$ & $27 \cdot 6$ & $58 \cdot 7 \pm \mathrm{I} \cdot 8$ & $30 \cdot 0$ & $73 \cdot 4 \pm \mathrm{I} \cdot 7$ & $23 \cdot 7$ & $80 \cdot 6 \pm 2 \cdot I$ & $26 \cdot 4$ \\
\hline $\mathrm{CH}$ & $52 \cdot 4 \pm \mathrm{I} \cdot 4$ & $27 \cdot \mathrm{I}$ & $52 \cdot 0 \pm \mathrm{I} \cdot 6$ & $30 \cdot 8$ & $66 \cdot 1 \pm \mathrm{I} \cdot 7$ & $26 \cdot 2$ & $78 \cdot 4 \pm 2 \cdot 2$ & $27 \cdot 5$ \\
\hline $\mathrm{AR} / \mathrm{CH}$ & $55^{\circ} \pm \mathrm{I} \cdot 4$ & $25 \cdot 9$ & $57 \cdot 4 \pm \mathrm{I} \cdot 8$ & $31 \cdot 3$ & $77^{\circ} 4 \pm \mathrm{I} \cdot 9$ & $24 \cdot 4$ & $84 \cdot 9 \pm 2 \cdot 2$ & $25 \cdot 5$ \\
\hline $\mathrm{CH} / \mathrm{AR}$ & $4^{8 \cdot I \pm I} \cdot 4$ & $29 \cdot \mathrm{I}$ & $48 \cdot 2 \pm \mathrm{I} \cdot 7$ & $35 \cdot 9$ & $67 \cdot 8 \pm 2 \cdot 0$ & $28 \cdot 9$ & $81 \cdot 9 \pm 2 \cdot 2$ & $27^{\circ} \mathrm{I}$ \\
\hline & $53 \cdot 5 \pm \mathrm{r} \cdot 6$ & $30 \cdot 3$ & $5 \mathrm{I} \cdot 7 \pm \mathrm{I} \cdot 7$ & $33 \cdot 3$ & $55^{2} \pm \mathrm{I} \cdot 5$ & $27 \cdot 7$ & $57 \cdot 9 \pm \mathrm{I} \cdot 7$ & $28 \cdot 7$ \\
\hline 234 & $50 \cdot 9 \pm \mathrm{r} \cdot 5$ & $28 \cdot 5$ & $54^{\cdot} \mathrm{I} \pm \mathrm{I} \cdot \dot{6}$ & $28 \cdot 7$ & $59^{\cdot} 8 \pm \mathrm{I} \cdot 4$ & $23 \cdot 8$ & $65 \cdot 4 \pm 2 \cdot 0$ & $30 \cdot 1$ \\
\hline
\end{tabular}

clear that mean longevities, 48-59 days on the 8 per cent. medium and 55-85 days on the 2 per cent. medium, are greater than any previously determined value at $25^{\circ} \mathrm{C}$., while the variabilities are smaller and more constant (Vetukhiv, I957; Tantawy and Vetukhiv, I96o; Dobzhansky, Lewontin and Pavlovsky, I964). Flies kept on suboptimal medium survived even longer than those on the optimal medium, and mean longevity in males was greater than in females. Analysis of variance showed quite significant effects of medium, population and sex, and also significant interactions between population and medium and between sex and medium. Although these differences are interesting, they have little bearing on estimating the values of $r_{m}$, since only a few flies die during the first 20 days of the adult life. This initial period makes the greatest contribution to the capacity for increase. The data on the longevities under different food conditions will be discussed in a separate paper; the relationships of longevity to body size, as well as 
the cytoplasmic influences on longevity, will be referred to in the next section together with the similar problem of fecundity.

\section{(v) Fecundity}

Lifetime egg production per female is summarised in table 8 and fig. I. Considerable differences between populations and between media are evident. Analysis of variance revealed a significant interaction between medium and population, in addition to significant main

TABLE 8

Female body size, lifetime fecundity per female, and the number of eggs laid in the first ro days of adult life

\begin{tabular}{|c|c|c|c|c|c|c|c|}
\hline & \multirow{3}{*}{$\begin{array}{c}\text { Popula- } \\
\text { tion }\end{array}$} & \multicolumn{3}{|c|}{8 per cent. medium } & \multicolumn{3}{|c|}{2 per cent. medium } \\
\hline & & \multirow{2}{*}{$\begin{array}{l}\text { Wing } \\
\text { length* }\end{array}$} & \multicolumn{2}{|c|}{$\begin{array}{l}\text { No. of } \\
\text { eggs per female }\end{array}$} & \multirow{2}{*}{$\begin{array}{l}\text { Wing } \\
\text { length }\end{array}$} & \multicolumn{2}{|c|}{$\begin{array}{l}\text { No. of } \\
\text { eggs per female }\end{array}$} \\
\hline & & & Mean \pm S.E. & C.V. & & Mean士S.E. & C.V. \\
\hline Lifetime & $\begin{array}{l}\text { AR } \\
\text { CH } \\
\text { AR/CH } \\
\text { CH/AR } \\
229 \\
234\end{array}$ & $\begin{array}{l}82 \cdot 65 \\
81 \cdot 13 \\
83 \cdot 08 \\
83 \cdot 23 \\
80 \cdot 80 \\
80 \cdot 35\end{array}$ & $\begin{array}{r}\text { I } 540 \cdot 5 \pm \text { I } 30 \cdot 6 \\
\text { I } 449.4 \pm \text { I } 35 \cdot 8 \\
\text { I } 433.9 \pm \text { I } 09 \cdot 5 \\
\text { I } 319.8 \pm \text { I } 07 \cdot 7 \\
786 \cdot 8 \pm 77.5 \\
985 . \text { I } \pm \text { I } 52 \cdot 9\end{array}$ & $\begin{array}{l}20 \cdot 8 \\
23 \cdot 8 \\
18 \cdot 7 \\
20 \cdot 0 \\
24 \cdot 1 \\
38 \cdot 0\end{array}$ & $\begin{array}{l}82 \cdot 43 \\
81 \cdot 08 \\
83 \cdot 05 \\
83 \cdot 13 \\
80 \cdot 58 \\
79 \cdot 80\end{array}$ & $\begin{array}{l}310 \cdot 2 \pm \text { I } 4 \cdot 6 \\
309 \cdot 6 \pm \text { I } 4 \cdot 6 \\
347^{\circ} 0 \pm \text { I } 8 \cdot 9 \\
313 \cdot 1 \pm 21 \cdot 1 \\
213 \cdot 7 \pm \text { I } 7 \cdot 9 \\
253 \cdot 7 \pm \text { I } 2 \cdot 2\end{array}$ & $\begin{array}{l}10 \cdot 5 \\
10 \cdot 5 \\
12 \cdot 2 \\
15 \cdot 1 \\
18 \cdot 3 \\
10 \cdot 8\end{array}$ \\
\hline $\begin{array}{l}\text { First } \\
\text { I o days }\end{array}$ & $\begin{array}{l}\text { AR } \\
\text { CH } \\
\text { AR/CH } \\
\text { CH/AR } \\
229 \\
234\end{array}$ & & $\begin{array}{rr}299^{\circ} 3 & 18 \cdot 4 \\
238 \cdot 4 \pm 20 \cdot 7 \\
282 \cdot 9 \pm 23 \cdot 0 \\
274 \cdot 1 \pm 19 \cdot 2 \\
206 \cdot 7 \pm 18 \cdot 5 \\
242 \cdot 7 \pm \quad 9 \cdot 4\end{array}$ & $\begin{array}{r}\text { I } 5 \cdot 0 \\
21 \cdot 3 \\
19 \cdot 9 \\
17 \cdot 2 \\
21 \cdot 9 \\
9 \cdot 5\end{array}$ & & $\begin{array}{l}44 \cdot 0 \pm 2 \cdot 4 \\
52 \cdot 7 \pm 5 \cdot 8 \\
50 \cdot 0 \pm 4 \cdot 7 \\
53 \cdot 0 \pm 3 \cdot 2 \\
52 \cdot 3 \pm 2 \cdot 4 \\
64 \cdot 4 \pm 3 \cdot 3\end{array}$ & $\begin{array}{l}12 \cdot 2 \\
24 \cdot 6 \\
20 \cdot 9 \\
13 \cdot 6 \\
10 \cdot 2 \\
11 \cdot 6\end{array}$ \\
\hline
\end{tabular}

* I unit $=0 \cdot 0208 \mathrm{~mm}$.

effects for these two factors (table 9). The source of the differences between the populations are chiefly the low fecundities in the two populations of Mather origin. On the 8 per cent. medium their lifetime fecundities were about half or two-thirds those of the four populations of Pinon Flat origin, and from two-thirds to three-fourths those on the 2 per cent. medium. The range of the lifetime egg production in Pinon Flat populations ( $1320-154$ I on the 8 per cent. medium) is the highest one ever recorded for this species at $25^{\circ} \mathrm{C}$. (Vetukhiv, I957; Tantawy and Vetukhiv, I96o; Dobzhansky, Lewontin and Pavlovsky, i964).

Comparing lifetime fecundity on the two media, different responses to decreases of the yeast concentration were found among the populations. In the two monomorphic populations the relations of the number of eggs on the 2 per cent. medium and that on the 8 per cent. medium were $20^{\circ} \mathrm{I}$ per cent. (AR) and $2 \mathrm{I} \cdot 4$ per cent. $(\mathrm{CH})$, while they were 24.2 per cent. $(\mathrm{AR} / \mathrm{CH})$ and 23.7 per cent. $(\mathrm{CH} / \mathrm{AR})$ in the two 


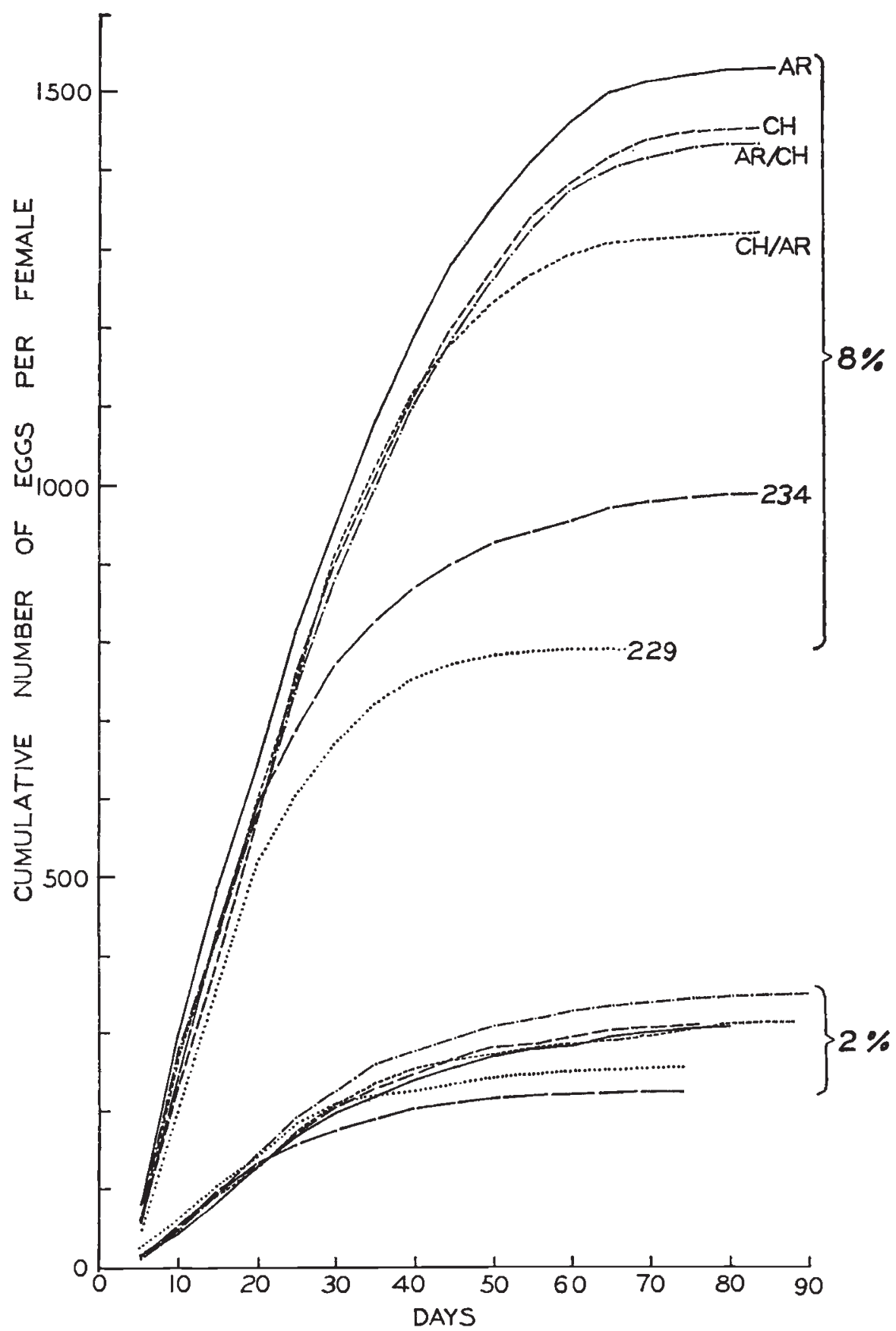

Fig. 1.-Average lifetime egg production per female in different populations on the 8 per cent. medium (above) and on the 2 per cent. medium (below). 
corresponding polymorphic populations. In the extremely polymorphic populations of Mather origin, the relations were 27.7 per cent. and 25.8 per cent. This suggests that polymorphic populations may

TABLE 9

Analysis of variance for lifetime fecundity per female

\begin{tabular}{|c|c|c|c|c|}
\hline Source & Sum of square & D.F. & Mean square & $\mathrm{F}$ \\
\hline $\begin{array}{l}\text { Medium } \\
\text { Population } \\
\text { Interaction } \\
\text { Error }\end{array}$ & $\begin{array}{r}15,099,33^{8} \\
1,804,038 \\
936,153 \\
2,688,048\end{array}$ & $\begin{array}{r}1 \\
5 \\
5 \\
54\end{array}$ & $\begin{array}{r}15,099,338 \\
360,808 \\
187,231 \\
49,778\end{array}$ & $\begin{array}{r}303 \cdot 33^{* * *} \\
7 \cdot 25^{* * *} \\
3 \cdot 76^{* * *}\end{array}$ \\
\hline Total & $20,527,577$ & 65 & & \\
\hline
\end{tabular}

be more homeostatic against changes in food conditions. As a result of these different responses among populations, the following orders of lifetime fecundity were observed:

$\mathrm{AR}>\mathrm{GH}>\mathrm{AR} / \mathrm{GH}>\mathrm{GH} / \mathrm{AR}>234>229 \quad$ (8 per cent. medium) $\mathrm{AR} / \mathrm{GH}>\mathrm{GH} / \mathrm{AR}>\mathrm{AR}>\mathrm{GH}>234>229$ (2 per cent. medium)

Since the fecundity is phenotypically correlated with the female body size (Robertson, I957; Tantawy and Vetukhiv, 1960), it is interesting to examine the differences in body size among the populations. As estimated from the wing length (table 8), the flies in the two highly polymorphic populations of Mather origin are smaller than

TABLE 10

Correlation coefficient between the mean values of female body size and lifetime fecundity or longevity

\begin{tabular}{|c|c|c|}
\hline & $\begin{array}{c}8 \text { per cent. } \\
\text { medium }\end{array}$ & $\begin{array}{c}2 \text { per cent. } \\
\text { medium }\end{array}$ \\
\hline $\begin{array}{l}\text { Wing size and lifetime fecundity } \\
\text { Wing size and longevity }\end{array}$ & $\begin{array}{c}0.688 \\
0 \cdot 172\end{array}$ & $\begin{array}{c}0.941^{* *} \\
0.877^{* *}\end{array}$ \\
\hline$* *$ P<0.01. & D.F. $=5$.
\end{tabular}

those in the four populations (two monomorphic and two polymorphic) from Pinon Flat strains. Among the populations of Pinon Flat origin, the flies in the monomorphic AR are significantly larger than in the monomorphic $\mathrm{GH}$ population, but slightly smaller than the two polymorphic populations. There is no difference attributable to the different media. Correlation coefficients between mean wing length and mean lifetime fecundity or the mean female longevity (table ro) are significant on the suboptimal 2 per cent. medium but not on the 
8 per cent. medium. The correlation between wing size and lifetime fecundity on the 8 per cent. medium was, however, close to the 5 per cent. level of significance.

For both fecundity (table 8 and fig. I) and longevity (table 7), consistent differences were found between the two polymorphic populations whose chromosomal constitutions should be identical. In all cases, the AR/CH population which as the cytoplasm of the AR strains showed significantly higher fecundity and longevity than did the $\mathrm{CH} / \mathrm{AR}$ population with the $\mathrm{CH}$-strain cytoplasm.

From the viewpoint of the estimation of $r_{m}$, the schedule of oviposition at different ages is more important than the total lifetime egg production, because the eggs laid in early days of adult life make most significant contributions to the capacity for increase. The egg-laying curves shown in fig. 2 are not smooth, because of the extensive fluctuations in daily number of eggs for each vial. This makes it difficult to find differences among the populations. However, analysis of the number of eggs laid during the first io days of the adult life (table 8) reveals some interesting differences. On the 8 per cent. medium the order of the first Io days fecundity is almost the same as that of lifetime fecundity, except for a low fecundity in the $\mathrm{CH}$ population. Comparing the three different groups of populations (monomorphic, polymorphic and those of Mather origin), the following order was found:

\section{Polymorphic $(\mathrm{AR} / \mathrm{CH}$ and $\mathrm{CH} / \mathrm{AR})>$ monomorphic}

$(\mathrm{AR}$ and $\mathrm{CH})>$ Mather (229 and 234).

On the 2 per cent. medium the differences between the groups were more pronounced and the order changed:

$$
\text { Mather }>\text { polymorphic }>\text { monomorphic. }
$$

It is evident that, at least on the suboptimal 2 per cent. medium, the more polymorphic the population, the more eggs are laid in the first Io days of adult life. The egg-laying schedules of the populations respond differently to the same changes in the medium conditions. It is important that there is no fixed relationship between the lifetime fecundity and the fecundity in the first io days.

\section{(vi) The innate capacity for increase}

The mean values of $r_{m}$, with their variances, standard errors and coefficients of variation, are given in table I I. The values of $r_{m}$ on the 8 per cent. medium $\left(0 \cdot 25^{6-0 \cdot 275)}\right.$ are definitely larger than those obtained in the experiments of Dobzhansky, Lewontin and Pavlovsky (I964). The values on 2 per cent. medium (o. I 53-0.165) are, however, smaller than those of the latter authors. To visualise the meaning of these differences in the value of $r_{m}$, the finite rate of increase $(\lambda=$ $\left.\operatorname{antilog}_{e} r_{m}\right)$, which means the multiplication of females per day, and the rate of multiplication per female in 20 days $\left(\lambda^{20}\right)$ are presented in fig. 3 for the data from three different experiments on Drosophila. It 
can be seen that small differences in $r_{m}$ could produce enormous differences in the actual number of flies in rather short periods of time.

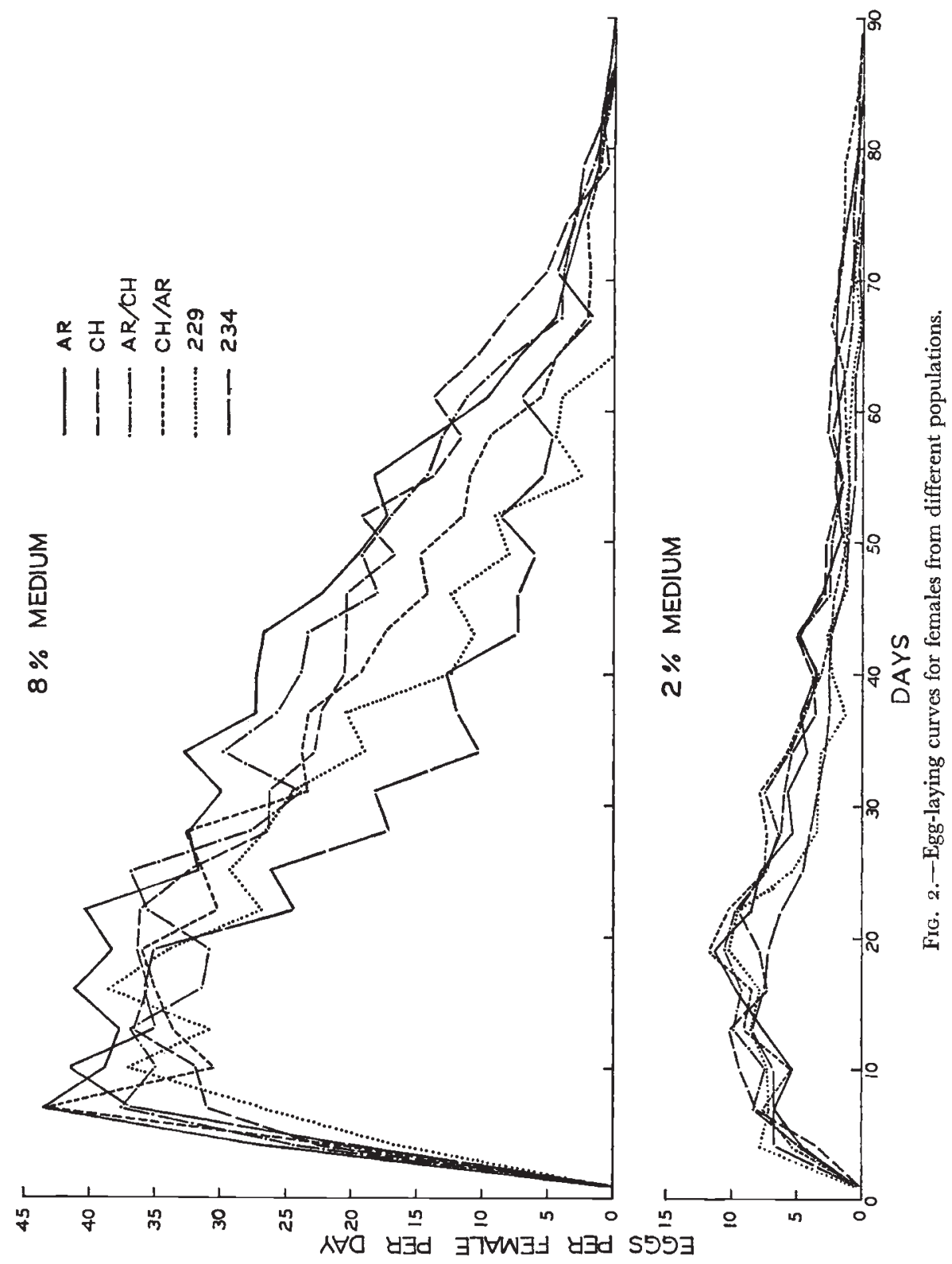

Although analysis of variance on $r_{m}$ has shown significant differences between populations on both media (table I2), these differences are too small and inconsistent in direction to make it possible to infer a relationship between the capacity for increase and the chromosomal 
constitution of a population. However, it may be noted that the variability of $r_{m}$ shows parallel systematic changes on both the 8 per cent. and the 2 per cent. media. Variances and coefficients of variation

TABLE I I

The innate capacity for increase $\left(\mathrm{r}_{\mathrm{m}}\right)$ and finite rate of increase

\begin{tabular}{|c|c|c|c|c|c|c|c|}
\hline \multirow{2}{*}{ Medium } & \multirow{2}{*}{ Population } & \multicolumn{5}{|c|}{ Innate capacity for increase } & \multirow{2}{*}{$\begin{array}{c}\text { Finite rate } \\
\text { of increase } \\
(\lambda)\end{array}$} \\
\hline & & $r_{m}$ & $S r$ & D.F. & S.E. & C.V. & \\
\hline \multirow{6}{*}{8 per cent. } & AR & 0.275 & 0.000II 95 & I 7 & 0.0027 & 4.0 & $I \cdot 3 I 6$ \\
\hline & $\mathrm{CH}$ & 0.263 & 0.0001212 & 17 & 0.0027 & $4 \cdot 2$ & $\mathrm{I} \cdot 3 \mathrm{OI}$ \\
\hline & $\mathrm{AR} / \mathrm{CH}$ & 0.269 & 0.000 I 639 & 17 & $0.003 \mathrm{I}$ & $4 \cdot 8$ & $I \cdot 309$ \\
\hline & $\mathrm{CH} / \mathrm{AR}$ & 0.266 & 0.0000680 & I 7 & 0.0020 & $3 \cdot 1$ & $I \cdot 305$ \\
\hline & 229 & 0.256 & $0.000054 \mathrm{I}$ & I9 & $0 \cdot 0017$ & $2 \cdot 9$ & $\mathrm{I} \cdot 29^{2}$ \\
\hline & 234 & $0.27 \mathrm{I}$ & 0.0000371 & I9 & 0.0014 & $2 \cdot 3$ & $\mathrm{I} \cdot 3 \mathrm{I} 2$ \\
\hline \multirow{6}{*}{2 per cent. } & AR & O.I 55 & $0 \cdot 000098 \mathrm{I}$ & I 6 & 0.0025 & $6 \cdot 4$ & $I \cdot I 66$ \\
\hline & $\mathrm{CH}$ & 0.164 & $0 \cdot 0000968$ & I 6 & 0.0025 & $6 \cdot 0$ & $I \cdot I 78$ \\
\hline & $\mathrm{AR} / \mathrm{CH}$ & 0.162 & $0.000044^{\circ}$ & I 6 & 0.0017 & $4^{\cdot I}$ & I 176 \\
\hline & $\mathrm{CH} / \mathrm{AR}$ & O.I 53 & 0.0000684 & I6 & $0.002 \mathrm{I}$ & $5 \cdot 4$ & $I \cdot 167$ \\
\hline & 229 & $0 \cdot 165$ & $0 \cdot 0000225$ & I 8 & 0.00 II & $2 \cdot 9$ & I'I 79 \\
\hline & 234 & 0.162 & 0.0000200 & I 8 & 0.0010 & $2 \cdot 8$ & $I \cdot I 76$ \\
\hline
\end{tabular}

are largest in the monomorphic populations ( $\mathrm{AR}$ and $\mathrm{CH}$ ), next in the polymorphic group (AR/CH and $\mathrm{CH} / \mathrm{AR}$ ) and smallest in the extremely polymorphic-Mather populations (229 and 234).

The relative importance of the different components in the determination of the value of $r_{m}$ is an interesting but difficult problem. To obtain some information about the relative weights of these components, the correlation coefficients between $r_{m}$ and the mean values of the components have been calculated. The ordering of these coefficients is for the 8 per cent. medium:

First ro days fecundity $\left(0.83^{* *}\right)$, lifetime fecundity $(0.590)$, longevity $(0.360)$, pre-adult viability $(0 \cdot 186)$, development time (o.093),

and for the 2 per cent. medium:

First Io days fecundity $(0.566)$, pre-adult viability $(0.476)$, development time $(-0.302)$, lifetime fecundity $\left(-0.43^{8}\right)$, longevity $(-0.456)$.

The number of degrees of freedom being small (5), a statistically significant positive correlation $(\mathrm{P}<\mathrm{O} \cdot \mathrm{OI})$ is obtained only for the early fecundity on the 8 per cent. medium. Differences in pre-adult viability and in development time on this medium are very small. On the suboptimal medium, both the early fecundity and the pre-adult viability may be important. Adult longevity and lifetime fecundity are 


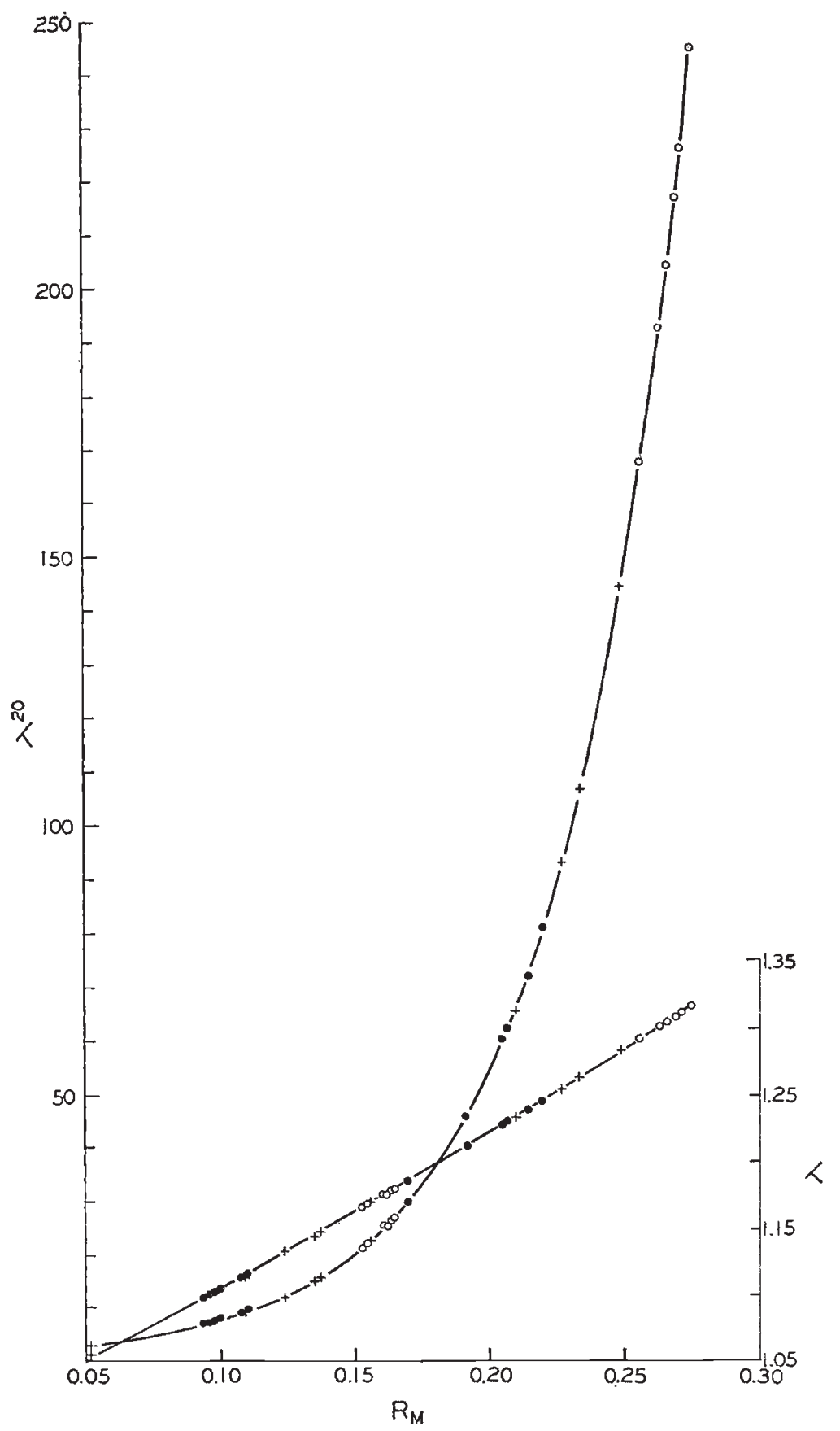

FIG. 3. The rates of increase expected in populations with different values of $r_{m}$. Birch et al. 1963: Dobzhansky et al. 1964: o present experiment. 
of relatively little significance. These conclusions generally agree with those of Birch, Dobzhansky, Elliott and Lewontin (1963) and Dobzhansky, Lewontin and Pavlovsky (1964).

TABLE I2

Analysis of variance for the value of $\mathrm{r}_{\mathrm{m}}$

\begin{tabular}{|c|c|c|c|c|c|}
\hline Medium & Source & Sum of square & D.F. & Mean square & F \\
\hline 8 per cent. & $\begin{array}{l}\text { Population } \\
\text { Error }\end{array}$ & $\begin{array}{l}0.00783 \\
0.009767\end{array}$ & $\begin{array}{r}5 \\
106\end{array}$ & $\begin{array}{l}0.00157 \\
0.0000921\end{array}$ & I $7 \cdot 04^{* *}$ \\
\hline 2 per cent. & $\begin{array}{l}\text { Population } \\
\text { Error }\end{array}$ & $\begin{array}{l}0.00415 \\
0.005682\end{array}$ & $\begin{array}{r}5 \\
100\end{array}$ & $\begin{array}{l}0 \cdot 000803 \\
0 \cdot 0000568\end{array}$ & $14.14^{* *}$ \\
\hline
\end{tabular}

** $\mathrm{P}<\mathrm{O} \cdot \mathrm{OI}$

\section{DISCUSSION}

In the present experiments the components of the innate capacity for increase were measured as precisely as practicable. Using the near-optimal 8 per cent. medium, the mean values of all the components, except the pre-adult viability, were found to be higher than any previously reported for $D$. pseudoobscura. On the contrary, the observed variabilities of the components were smaller than found by previous investigators. All estimates of $r_{m}$ on the 8 per cent. medium (table I I) are considerably greater than any observed by Dobzhansky, Lewontin and Pavlovsky (1964); they are probably close to the maximal values of which the species is capable. The highest $r_{m}, 0.275$, implies that in a population having unlimited food and space a female can multiply $1 \cdot 316$ times per day and produce 245 flies in 20 days, a period shorter than the generation length. This is not only greater than any value formerly obtained for $D$. pseudoobscura but also for $D$. serrata, a species with an appreciably more rapid development (Birch, Dobzhansky, Elliott and Lewontin, I963). The 2 per cent. medium gives, as expected, much lower estimates of $r_{m}$, although as will be shown in another publication, this medium is only suboptimal and in more stringent conditions, such as a I per cent. yeast medium, still lower values may be expected. The range of $r_{m}$ values which can be realised with different food conditions is probably wider than that with different temperatures within a tolerable range.

While Dobzhansky, Lewontin and Pavlovsky (r964) found higher $r_{m}$ values in chromosomally polymorphic than in chromosomally monomorphic populations, this is not apparent in the present experiments. It may well be that the fitness advantages of polymorphism are removed under optimal conditions, thus making poly- and monomorphic populations equivalent. The suboptimal medium used in our experiments ( 2 per cent. yeast) is very different from that used by the authors mentioned above. More data on the influence of different 
kinds of food media on chromosomal polymorphism in experimental populations is desirable. It is interesting that apparently significant differences exist between the populations for lifetime fecundity and for fecundity during the first Io days of adult life, and that these differences are not the same on the 8 per cent. and on the 2 per cent. food media (table 8).

\section{SUMMARY}

I. The different components which contribute to the innate capacity for increase $\left(r_{m}\right)$ were studied in a series of chromosomally polymorphic and monomorphic populations of Drosophila pseudoobscura.

2. Efforts were made to obtain optimal and suboptimal conditions for these populations; in this respect the experiments here described differ from those of Dobzhansky, Lewontin and Pavlovsky (1964) in which stringent conditions were deliberately imposed.

3. At optimal conditions very high $r_{m}$ values were observed.

4. Chromosomally polymorphic and monomorphic populations did not differ significantly under either optimal or suboptimal conditions.

Acknowledgments.--The author expresses his gratitude to Professor Theodosius Dobzhansky for his advice and encouragement during the course of experiments and in the preparation of the manuscript. This work could not be completed without the help of Professor R. G. Lewontin, the University of Chicago, who kindly computed the estimates of the $r$ values. It is a pleasure to acknowledge the gratitude to him, and to $\mathrm{Mr} \mathrm{W}$. W. Anderson for their valuable suggestions and help.

\section{REFERENCES}

ANDERson, w. w. 1966. Genetic divergence in M. Vetukhiv's experimental populations of Drosophila pseudoobscura. 3. Divergence in body size. Genet. Res., 7, 255-266.

ANDREWARTHA, H. G., AND BIRCH, L. C. 1954. The distribution and abundance of animals. Chicago University Press.

ayala, F. J. I965a. Relative fitness of populations of Drosophila serrata and Drosophila birchii. Genetics, 5I, 527-544.

AYALA, F. J. $1965 b$. Evolution of fitness in experimental populations of Drosophila serrata. Science, 150, 903-905.

BARKER, J. S. F. I963. The estimation of relative fitness of Drosophila populations. II. Experimental evaluation of factors affecting fitness. Evolution, $17,56-7 \mathrm{I}$.

BARKER, J. S. F. I965. The estimation of relative fitness of Drosophila populations. IV. Experiments on D. pseudoobscura. Genetics, 5I, 747-759.

Battaglia, B., AND smith, H. I96I. The Darwinian fitness of polymorphic and monomorphic populations of Drosophila pseudoobscura at $16^{\circ}$ G. Heredity, 16 , $475-484$.

BEARDMORE, J. A., DOBZhaNSKy, TH., AND PAVlovsky, o. A. 1960. An attempt to compare the fitness of polymorphic and monomorphic experimental populations of Drosophila pseudoobscura. Heredity, 14, 19-33.

BIRCH, L. C. 1948. The intrinsic rate of natural increase of an insect population. Four. Animal Ecol., 17, I5-26.

BIRCH, L. D., DOBZhANSKY, TH., ELLIOTT, P. O., AND LEWONTIN, R. C. I963. Relative fitness of geographic races of Drosophila serrata. Evolution, $17,72-83$.

DOBZHANSKy, TH., LEWONTIN, R. C., AND PAVlOVSKy, O. 1964. The capacity for increase in chromosomally polymorphic and monomorphic populations of Drosophila pseudoobscura. Heredity, 19, 597-614. 
oHbA, s. 196r. Analytical studies on the experimental populations of Drosophila. I. The effect of larval population density upon the pre-adult growth in $D$. melanogaster and $D$. virilis with special reference to their nutritional conditions. Biol. Jour. Okayama Univ., 7, 87-1 25.

Robertson, F. W. 1957. Studies in quantitative inheritance. XI. Genetic and environmental correlation between body size and egg production in Drosophila melanogaster. Four. Genet., 55, 428-443.

SPASsKy, в. 1943. Cream of wheat-molasses fly medium. D. I. S., I7, 67-68.

STRIGKBERGER, M. w. 1963a. Evolution of fitness in experimental populations of Drosophila pseudoobscura. Evolution, 17, 40-55.

STRIGKBERGER, M. w. $1963 b$. Comparative fitness of experimental populations of Drosophila pseudoobscura. Heredity, 18, 385-395.

TANTAWY, A. o. 196I. Effects of temperature on productivity and genetic variance of body size in populations of Drosophila pseudoobscura. Genetics, 46, 227-238.

TANTAWY, A. o., AND vetukHiv, M. o. I96o. Effects of size on fecundity, longevity and viability in populations of Drosophila pseudoobscura. Amer. Nat., 94, 395-404. vetukHiv, M. I956. Fecundity of hybrids between geographic populations of Drosophila pseudoobscura. Evolution, IO, I39-146.

VETUKHiv, M. I957. Longevity of hybrids between geographic populations of Drosophila pseudoobscura. Evolution, II, 348-36o.

WALLACE, B. 1959. Studies of the relative fitness of experimental populations of Drosophila melanogaster. Amer. Nat., 93, 295-314. 